Supporting Information

\title{
Highly Diastereoselective Strecker Reaction of Enolizable Aliphatic Sulfinimines
}

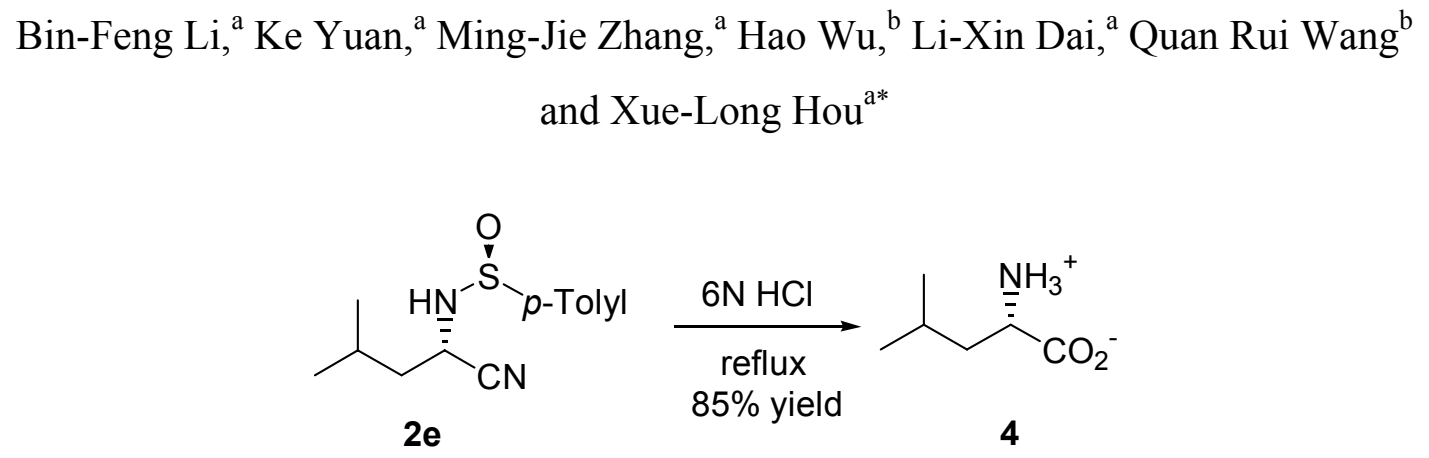

Hydrolysis of $\left(S_{s}, S\right)-1-\left(p\right.$-Toluenesulfinylamino)-3-methylpentanenitrile $2 \mathrm{e}^{1}$ To an aqueous solution of $\mathrm{HCl}(6 \mathrm{~N}, 10 \mathrm{~mL})$ was added sulfinylamino nitrile $2 \mathrm{e}(500 \mathrm{mg}, 2 \mathrm{mmol},>98 \% \mathrm{de})$ obtained from the Strecker reaction of $(S)-(+)-\mathrm{N}-($ iso-butylidene)- $p$-toluenesulfinamide and purified by chromatography (elute: acetone $: \mathrm{CH}_{2} \mathrm{Cl}_{2}: \mathrm{n}$-hexane $=5: 25: 70$ ). The resulting mixture was stirred at reflux for $6 \mathrm{~h}$. The reaction mixture was diluted with water $(10 \mathrm{~mL})$ and extracted with ether $(10 \mathrm{~mL} \mathrm{X} \mathrm{3)}$. The aqueous solution was concentrated to ca. $2 \mathrm{~mL}$ and purified with ion exchange resin (Dowex 50X8-500, elute: $1.5 \mathrm{~N} \mathrm{NH}_{3}-\mathrm{H}_{2} \mathrm{O}$ ) provided L-leucine 4 : $223 \mathrm{mg}, 85 \%$ yield. 97\% ee, HPLC: Daicel Crownpark (+), aqueous $\mathrm{HClO}_{4}, \mathrm{pH}=2$, flow rate $0.80 \mathrm{~mL} / \mathrm{min}, \quad t \mathrm{R}: 3.6 \mathrm{~min}(D)$-isomer and $5.1 \mathrm{~min}(L)$-isomer, detection at $210 \mathrm{~nm}$. $[\alpha]_{\mathrm{D}}{ }^{20}=$ $+15.8(\mathrm{c} 1.2,6 \mathrm{~N} \mathrm{HCl}),\left[{ }_{1 i t .:}{ }^{2}[\alpha]_{\mathrm{D}}{ }^{20}=+15.3\right.$ (c 3.96, 6N HCl]. ${ }^{1} \mathrm{H}-\mathrm{NMR}\left(\mathrm{D}_{2} \mathrm{O}, 300 \mathrm{MHz}\right): \delta 0.97$ (m, $6 \mathrm{H}), 1.71-1.75(\mathrm{~m}, 3 \mathrm{H}), 3.70(\mathrm{~m}, 1 \mathrm{H})$.

\section{References:}

1. Davis, F. A.; Reddy, R. E.; Portonovo, P. Tetrahedron Lett. 1994, 35, 9351.

2. DeWitt, H. D.; Ingersoll, A. W. J. Am. Chem. Soc. 1951, 73, 3359. 